\title{
Ein Fall für Luca Clemente
}

\section{Erhard Taverna}

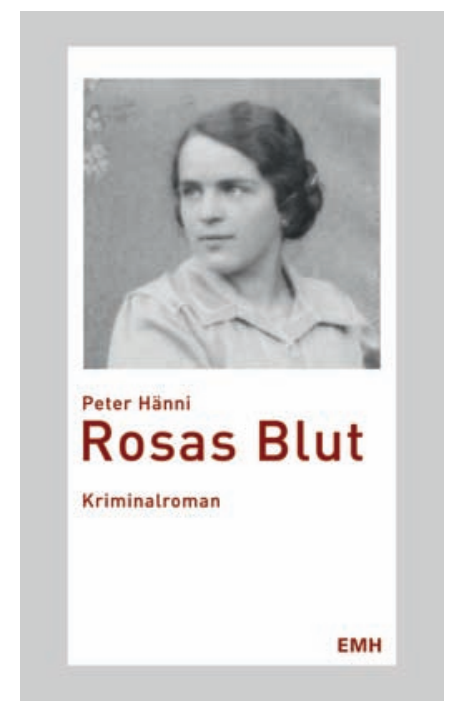

Möchten Sie sich selbst auf die Suche nach dem Täter machen? Dann haben Sie ab der nächsten Ausgabe die Möglichkeit einer Leseprobe. Oder Sie bestellen das Buch gleich auf www.emh.ch/books oder über Tel. 0614678575 .
Zeiten und Orte sind klar festgelegt. Die realen und fiktiven Koordinaten kreuzen sich in Montella. Ein kleines Dorf südlich von Neapel am Fusse des Monte Sassetano, Geburtsort der Mutter des Autors Peter Hänni, geboren 1958. Aus einer privaten Familiengeschichte habe er den Kern seines Kriminalromans «Rosas Blut» entwickelt, und auch eine Rosa habe es gegeben, aus einer reichen Familie, enterbt und verstossen, wie im Roman, nur weil sie den Falschen heiratete. Doch weiter gehen die Analogien nicht, versichert der HNO-Spezialist aus Solothurn, dessen Hauptfigur und alter ego Luca Clemente mit chirurgischer Präzision einem Mordfall im engsten Familienkreis auf der Spur ist. Aus den familiären Koordinaten wird ein Schachbrett, auf dem die Figuren nach logischen Regeln ein durchdachtes Spiel zum intellektuell und emotional befriedigenden Ende führen. Auf der Suche nach dem Täter ist die Geschichte nach dem klassischen Muster berühmter Vorgänger gebaut. Sie folgt einem präzisen Handlungsablauf und hält dabei eine Spannung aufrecht, die den Leser bis zur letzten Zeile am Haken des Krimischreibers zappeln lässt. Sie bietet eine sympathische Identifikationsfigur mit ihren Stärken und Schwächen, eine überschaubare Erzählstruktur, spannende Nebenhandlungen und überraschende Wendungen. Sie belohnt die Leserinnen und Leser, indem am Ende des Labyrinths wieder Ordnung in einer unordentlichen Welt entsteht.

Peter Hänni mischt gekonnt süditalienisches Ambiente mit herbstlichem Aarenebel, Tragödien und Intrigen mit Schuld und Sühne, er wechselt souverän Schauplätze und Zeitebenen und stachelt dabei unablässig unsere Neugierde an. Wir können nicht mehr anders, wir müssen weiterlesen. Er jongliert geschickt mit seinem medizinischen Können und erweitert dabei spielerisch unser Wissen über das Rückkoppelungspfeifen eines Hörgerätes, die gerichtsmedizinischen Methoden einer Virtopsie, die Diagnose eines akuten Pneumatozephalus oder das organisatorische Regelwerk einer onkologischen Behandlung. Zum Arsenal der Mordwaffen gehört ein zweckentfremdetes Instrument, dessen normale Verwendung hier nicht verraten sei. Es hat dem Autor sichtlich Vergnügen bereitet eine tödliche Verletzung in mörderischer Absicht herbeizuführen, die im täglichen Operationsablauf ein absolut zu vermeidendes Risiko bedeutet. Was der Chirurg Hänni niemals darf, kann der Schriftsteller Hänni krea-

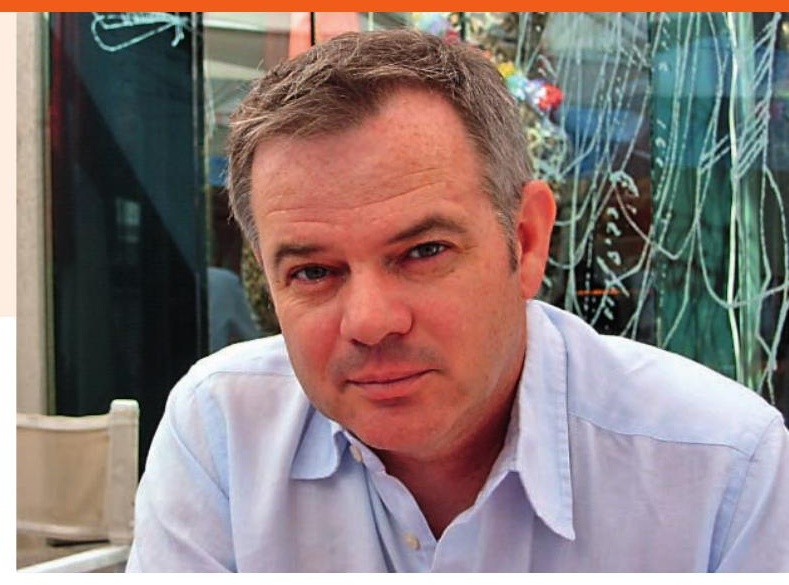

tiv ausleben. Abends beim Einschlafen, wenn es knistert, mit Filzstift und Diktiergerät, oder an Wochenenden und in den Ferien.

\section{«Rosas Blut» von Peter Hänni:}

\section{der erste Krimi im Schweizerischen}

\section{Ärzteverlag EMH}

Wie jedes Buch hat auch dieses Werk seine eigene Geschichte. Sie begann mit einer ersten Fassung unter einem anderen Titel, vor wenigen Jahren, die mit dem Konkurs des Onlineverlages und einigen Restexemplaren endete. Peter Hänni verteilte diese Bücher über den Freundeskreis hinaus an die Solothurner Zeitung und eine Buchhandlung. Aus dem Verkaufserfolg und zahlreichen positiven Rückmeldungen entstand das Projekt einer zweiten, gründlich lektorierten und überarbeiteten Fassung. Daraus hervorgegangen ist ein spannender Kriminalroman, der trotz der erdrückenden Überfülle einer seit Jahren boomenden Buch- und Filmproduktion des medical thriller eine unverwechselbare, eigene Handschrift trägt. Die Erzählung vermeidet alle Todsünden der immer zahlreicheren und allzu oft langweiligen Sozio-Frauen-Katzen-Justiz-Regional-SchwedenVenedig-China-Wirtschafts-Schwulen-Noir-Hardboiled-Psycho-Mittelalter-Esoterik-SerienkillerKriminalromane. Dafür sind wir Peter Hänni sehr dankbar und wünschen «Rosas Blut» die gebührende Verbreitung. Nur die letzten Zeilen lassen uns im Stich. Der Übeltäter hat mit einem hämischen Grinsen gestanden. Luca steht auf und greift nach seinem Mantel. «Ich muss telefonieren», sagte er leise, bevor er den Raum verliess. Dann ist definitiv Schluss, und wir fragen uns vergeblich: Wem? Seiner Ehefrau oder Sara, seiner Praxishilfe, oder dem Finanzberater?

Ersttäter schlagen wieder zu. Ein zweites Manuskript liegt bereits in der Schublade. Eine Fortsetzung sei es nicht, doch einige vom Personal werden wieder beschäftigt. Mehr will uns der Kollege nicht verraten. 